\title{
The use of posts in endodontically treated teeth among Nepalese Prosthodontists.
}

Khanal $\mathrm{B}^{1}$, Adhikari B ${ }^{2}$

${ }^{1}$ Assistant Professor, Department of Prosthodontics, Chitwan Medical College, Bharatpur, Nepal

${ }^{2}$ Assistant Professor, Department of Conservative Dentistry and Endodontics, Chitwan Medical College, Bharatpur, Nepal

\begin{abstract}
Introduction: One of the most studied and researched subject in dentistry is restoration of endodontically treated tooth. The success of an endodontically treated tooth depends not only good endodontic therapy but is equally if not more dependent on the nature, type and execution of post endodontic restorations. The purpose of this study was to know the opinions, techniques, and materials used by Nepalese Prosthodontists for restoring endodontically treated teeth with a post.

Materials and Methods: A nationwide survey was performed among Nepalese Prosthodontists through electronic communication media by distributing a questionnaire to find out the various treatment strategies, post types and materials being used by them. Descriptive statistics were used to analyze the responses given by the Prosthodontists by using SPSS Statistical software package (version 21.0). Results: A total of 69 returned questionnaire out of the 114 sent were included in the study. Majority of the respondents were in the age group of $31-40 \mathrm{yrs}(70.6 \%, \mathrm{~N}=48) .51 \%$ of the respondents were male and $49 \%$ were female. Out of the responses analyzed, $91 \%(\mathrm{~N}=63)$ think that the primary purpose of a post is to retain a core. The quantity of remaining tooth structure affects the decision to place a post $(98.5 \%, \mathrm{~N}=68)$. The ideal post length for $81.2 \%(\mathrm{~N}=56)$ respondents was $2 / 3^{\text {rd }}$ the root length. $55 \%(\mathrm{~N}=38)$ respondents think that $4-5 \mathrm{~mm}$ of apical Gutta Percha should be left during post space preparation. The preferred type of post was custom cast metal post for $69.5 \%(\mathrm{~N}=48)$ and prefabricated fiber reinforced post for $66.6 \%(\mathrm{~N}=46) .55 \%(\mathrm{~N}=38)$ respondents preferred passive type of post. Out of the respondents $72 \%(\mathrm{~N}=50)$ were using Glass Ionomer Cement for cementing cast posts and $91 \%$ $(\mathrm{N}=63)$ of them were using resin cement for fiber reinforced posts. The most popular core build-up material was dual cured composite resin $(63.8 \%, \mathrm{~N}=44)$.

Conclusion: Although the results obtained cannot give a definitive guide for restoration of endodontically treated teeth with a post, it pictures how the Nepalese Prosthodontists are practicing posts for restoring endodontically treated teeth. The varied responses obtained here can be taken into consideration to conclude that the preference of techniques and materials depends upon the individual clinician and the clinical scenario.
\end{abstract}

Key words: Nepalese prosthodontists; Endodontically treated tooth; Post; Questionnaire.

\section{Introduction}

$\mathrm{O}$ ne of the most studied and researched subject in dentistry is restoration of

Conflict of Interest: No

\section{*Corresponding Author}

Dr. Bibek Khanal, Assistant Professor

Department of Prosthodontics, Chitwan Medical

College, Bharatpur, Nepal

E-mail:bibekpros@gmail.com endodontically treated tooth. Although there has been an extensive and vast research and excavation in this topic there remains a sense of dilemma, controversy and mixed opinion on the optimum treatment planning for treating an endodontically treated tooth. There are conflicting literature available, some of which suggest the need of posts for endodontically treated teeth while others suggest the other way and we can find several studies which direct towards placing a post or not placing it 
depending upon the amount of tooth structure remaining after endodontic therapy. ${ }^{1-7}$

The success of an endodontically treated tooth depends not only good endodontic therapy but is equally if not more dependent on the nature, type and execution of post endodontic restorations like direct restorations (e.g. composite, amalgam), crowns, post and core etc. ${ }^{2,5,8-10}$ The importance of remaining cervical tooth structure after endodontic therapy is well known for many years and plays an important role in creating ferrule effect. We can find and study divided view and conflict in the requirement of ferrule effect for restoring an endodontically treated tooth with a post and core. ${ }^{11-13}$

There is a vast collection of post material and systems, different types of luting cements, different techniques and philosophies for preparing a post space and different methods of making an impression of the post space available and taught since many years in dental schools and is being practiced by dental practioners. ${ }^{1,2}$, 6-10, 13 Yet there is no consensus among dental practitioners for the choice of treatment options for treating an endodontically treated tooth.

There have been several studies among various dental professionals on their knowledge, attitude and clinical practice on post and core therapy on endodontically treated tooth in the past and these studies can give us some insight about the status of post and core therapy on those countries and regions. ${ }^{14-23}$ This present study aims towards finding out the scenario of treatment of endodontically treated tooth with post and core by Prosthodontists of Nepal.

\section{Materials and Methods}

The proposal of the study was submitted to Institutional Review Committee of Chitwan Medical College and ethical clearance was obtained (IRC No: CMC-IRC/077/078-040). A questionnaire was prepared based on previous similar studies and it was modified according to scenario of Nepal. ${ }^{14-20,23}$

Convenience sampling method was selected in this study. For collection of data a Google form was created with the questionnaire along with a consent section and the message containing link to it was sent to 114 Prosthodontists through electronic communication media (Viber, Messenger and Whatsapp). The list of the Prosthodontists was obtained from Nepalese Prosthodontic Society webpage and other open listed sources. The questionnaire consisted of two parts, the $1^{\text {st }}$ one consisted the sociodemographic characteristics of the participants while the $2^{\text {nd }}$ part consisted of 15 open as well as close ended questions related to how they are using posts in endodontically treated teeth. The participants were allowed for selecting more than one options whenever applicable. All Prosthodontists practicing in Nepal and registered in Nepal Medical council were included in this study, while Prosthodontists not practicing anymore in Nepal and who weren't willing for the study were excluded. Reminder messages were resent for non-responding Prosthodontists. The returned questionnaires were filled in Excel sheet and descriptive statistical analysis (frequency and percentage) was done using SPSS Statistical Software Package (version 21.0).

\section{Results}

Out of 114 Prosthodontists to whom the questionnaire was sent for fill-up, there was 72 responses. Out of those 72 responses, 3 responses were repeated by the same participants. Finally 69 responses were considered for data analysis in this study which represented $60.52 \%$ response rate.

Among the respondents, majority of them $(70.6 \%, N=48)$ were in the age group of $31-40$ yrs. The distribution of the Prosthodontists by their age group are presented in Figure 1. 
Regarding the gender of the participants 51\% $(\mathrm{N}=35)$ were male while $49 \% \quad(\mathrm{~N}=34)$ were female.

When asked about their type of practice, $40 \%$ $(\mathrm{N}=28)$ were involved in teaching institute only, $21 \%(\mathrm{~N}=15)$ were involved in teaching institute as well as private practice, $20 \%(\mathrm{~N}=14)$ were involved in private practice, $16 \%(\mathrm{~N}=10)$ were involved in government hospital. (Table 1)

Majority of the respondents $(59 \%, N=41)$ in this study had obtained their degree from Nepal, while $41 \%(\mathrm{~N}=28)$ had obtained degree from universities abroad.

The distribution of the Prosthodontists according to their years of experience is illustrated in Figure 4.

Out of the 69 respondents, a majority of them $(91 \%, N=63)$ think that the primary purpose of a post is to retain core. Likewise $40 \%(28)$ also think that a post can reinforce an endodontically treated tooth while $31 \%(\mathrm{~N}=22)$ think that post doesn't reinforce an endodontically treated tooth.(Figure 5)

For deciding whether or not to place a post, a majority $98.5 \%(\mathrm{~N}=68)$ of the respondents decide it on the basis of the quantity of remaining tooth structure left, while $60 \%(\mathrm{~N}=42)$ also take the type of planned restoration for deciding and $49 \%(\mathrm{~N}=34)$ decide placement of post on the basis of location of tooth in the arch. (Figure 6)

Similarly Figure 7 represents the frequency of post placement according to tooth position, which shows that post placement is done more frequently in maxillary anteriors $67 \%(\mathrm{~N}=46)$ and $46 \%(\mathrm{~N}=32)$ respondents rarely place post in mandibular anteriors.

When asked about the post length, 81.2\% $(\mathrm{N}=56)$ of the respondents think that the ideal post length should be $2 / 3^{\text {rd }}$ the root length, 30.4 $\%(\mathrm{~N}=21)$ think it should be longer than the length of crown and $27.4 \%(\mathrm{~N}=19)$ think it should be equal to length of crown. (Table 2)

Similarly, 67\% (N=46) respondents prefer taking incisal/occlusal height of remaining tooth structure as clinical reference point for measuring length of the post, while $21 \%(\mathrm{~N}=15)$ prefer floor of pulp chamber and $13 \%(\mathrm{~N}=9)$ prefer crestal bone for the same. (Figure 8)

Out of all the respondents 55\% ( $\mathrm{N}=38)$ think that 4-5 mm of Gutta Percha (GP) should be left as apical seal, while $38 \%(\mathrm{~N}=26)$ think that 2-3 $\mathrm{mm}$ of GP is enough. Similarly $6 \%(\mathrm{~N}=4)$ think that it should be more than $5 \mathrm{~mm}$ and only $1.4 \%$ $(\mathrm{N}=1)$ think that less than $2 \mathrm{~mm}$ is enough. (Figure9)

For establishing the post diameter $56 \%(\mathrm{~N}=39)$ prefer confirming it to existing canal diameter, while $35 \% \quad(\mathrm{~N}=24)$ prefer preparing apical portion while confirming to the existing canal diameter. Similarly $11 \%(\mathrm{~N}=8)$ prefer to increase diameter to fit prefabricated type post, $9 \%$ $(\mathrm{N}=6)$ prefer to increase diameter to strengthen post and only $1.4 \%(\mathrm{~N}=1)$ respondent prefer to leave $1 \mathrm{~mm}$ amount of remaining dentin while establishing post diameter. (Table 3 )

Similarly Figure 10 shows the respondents' preference for establishing post geometry.

Figure 11 shows the respondents' preference for post type in their clinical practice. Here the preference is more towards custom cast metal $69.5 \%(\mathrm{~N}=48)$ and prefabricated fiber reinforced type of post $66.6 \%(\mathrm{~N}=46)$.

For fabricating custom cast posts $45 \%(\mathrm{~N}=31)$ respondents use direct pattern technique (Resin/wax), 20\% (N=14) use indirect method (impression) and 35\% ( $\mathrm{N}=24)$ use both method. (Figure 12)

Similarly, 55\% (N=38) of the Prosthodontists preferred serrated/rough (passive) type of post, $36 \%(\mathrm{~N}=25)$ preferred smooth (passive) type and $9 \%(\mathrm{~N}=6)$ preferred screw/threaded (active) type of post. (Table 4) 
The preferred timing of radiograph to be taken by the Prosthodontists is illustrated in Table 5.

In this survey only 4 respondents (6\%) mentioned that they routinely use a rubber dam while the majority of them i.e. 65 (94\%) respondents don't use a rubber dam.

The choice of luting cement according to the post type is presented in Figure 13. Here it is clear that majority use Glass Ionomer Cement (GIC) for cementation of cast post $(72 \%, \mathrm{~N}=50)$ and prefabricated metal $(46 \%, \mathrm{~N}=32)$ post while resin luting cement is used by a whopping $91 \%$ $(\mathrm{N}=63)$ for cementation of fiber reinforced post.

The material used for core build-up after placing prefabricated post was resin composite

Table 1: Distribution of participants by type of practice

\begin{tabular}{|l|c|}
\hline Options & Responses \\
\hline Teaching Institute & 28 \\
\hline Private practice +Teaching Institute & 15 \\
\hline Private Practice & 14 \\
\hline $\begin{array}{l}\text { Government Hospital +Private } \\
\text { practice }\end{array}$ & 1 \\
\hline Government Hospital & 10 \\
\hline Blank & 1 \\
\hline
\end{tabular}

Table 2: Responses for the question "What should be the ideal post length?"

\begin{tabular}{|l|c|}
\hline Options & Responses \\
\hline Equal to length of crown & $19(27.5 \%)$ \\
\hline Longer than length of crown & $21(30.4 \%)$ \\
\hline Half the root length & $2(2.9 \%)$ \\
\hline $2 / 3^{\text {rd }}$ the root length & $56(81.2 \%)$ \\
\hline $4 / 5^{\text {th }}$ the root length & $3(4.3 \%)$ \\
\hline $\begin{array}{l}\text { As long as possible without } \\
\text { damaging the apical seal }\end{array}$ & $13(18.8 \%)$ \\
\hline $\begin{array}{l}\text { As long as possible keeping apical 3 } \\
\text { mm seal }\end{array}$ & $1(1.4 \%)$ \\
\hline Depends on ferrule length & $1(1.4 \%)$ \\
\hline Apical seal of minimum 3 mm & $1(1.4 \%)$ \\
\hline 5mm apical seal should remain & $1(1.4 \%)$ \\
\hline 3-4 mm below crestal bone height & $1(1.4 \%)$ \\
\hline $\begin{array}{l}\text { Minimum 5 mm apical seal should } \\
\text { be maintained }\end{array}$ & $1(1.4 \%)$ \\
\hline
\end{tabular}

(dual cured) for $63.8 \%(\mathrm{~N}=44)$ respondents, light cured resin composite for $24.6 \%(\mathrm{~N}=17)$, amalgam for $7.2 \%(\mathrm{~N}=5)$ and resin modified GIC for $2.9 \%(\mathrm{~N}=2)$ of the total respondents. (Table 6)

Table 3: Response for the question "What do you prefer for establishing post diameter?"

\begin{tabular}{|l|c|}
\hline Options & Responses \\
\hline $\begin{array}{l}\text { Confirming to existing canal } \\
\text { diameter }\end{array}$ & 39 \\
\hline $\begin{array}{l}\text { Confirming to existing canal } \\
\text { diameter with preparation of the } \\
\text { apical portion }\end{array}$ & 24 \\
\hline $\begin{array}{l}\text { Increasing diameter to strengthen } \\
\text { post }\end{array}$ & 6 \\
\hline $\begin{array}{l}\text { Increasing diameter to fit } \\
\text { prefabricated type post }\end{array}$ & 8 \\
\hline Amount of remaining dentin $=1 \mathrm{~mm}$ & 1 \\
\hline
\end{tabular}

Table 4: Preference of post surface texture by the participants.

\begin{tabular}{|l|c|}
\hline Options & Responses \\
\hline Screw/ Threaded (active) & 6 \\
\hline Serrated/Rough (Passive) & 38 \\
\hline Smooth(Passive) & 25 \\
\hline
\end{tabular}

Table 5: Response for the timing of radiograph by the participants

\begin{tabular}{|l|c|c|}
\hline $\begin{array}{l}\text { When do participants take } \\
\text { radiographs }\end{array}$ & Yes & No \\
\hline Post endodontic treatment & 61 & 0 \\
\hline Before post preparation & 52 & 5 \\
\hline During post preparation & 58 & 0 \\
\hline After post placement & 63 & 2 \\
\hline
\end{tabular}

Table 6: Responses for preference of core build up material for prefabricated post.

\begin{tabular}{|l|c|}
\hline Options & Responses \\
\hline Resin composite (dual cured) & $44(63.8 \%)$ \\
\hline Resin composite (light cured) & $17(24.6 \%)$ \\
\hline Amalgam & $5(7.2 \%)$ \\
\hline $\begin{array}{l}\text { Resin modified Glass Ionomer } \\
\text { Cement }\end{array}$ & $2(2.9 \%)$ \\
\hline Glass Ionomer Cement & 0 \\
\hline Others (but not specified) & $1(1.4 \%)$ \\
\hline
\end{tabular}




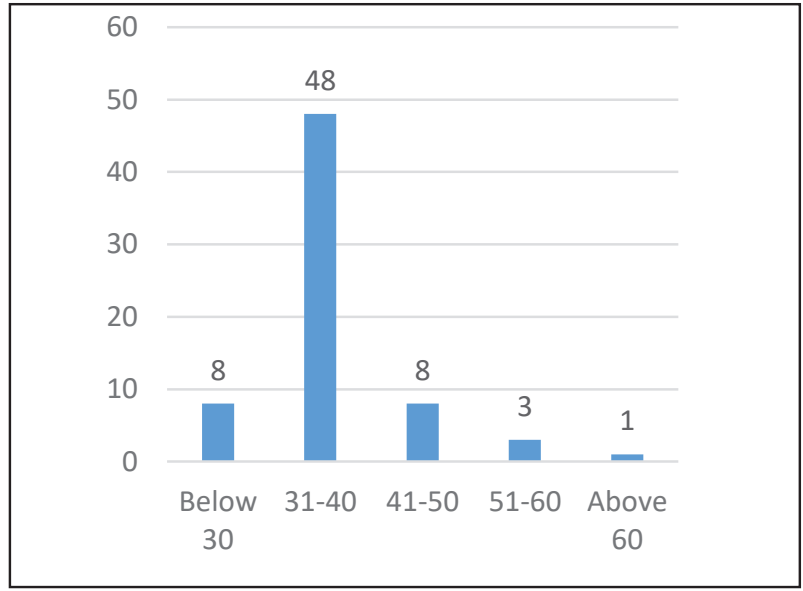

Figure 1: Age Group of Participants

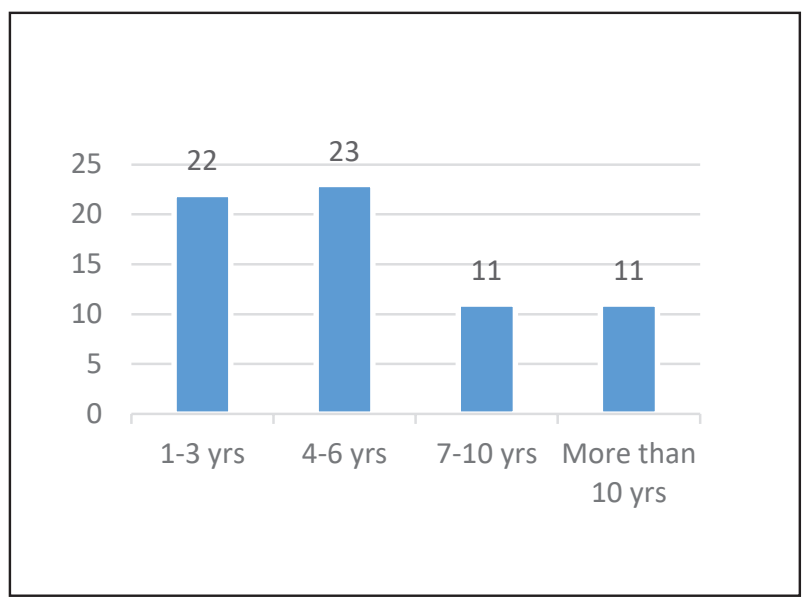

Figure 3: Distribution of participants according to their experience as a Prosthodontist

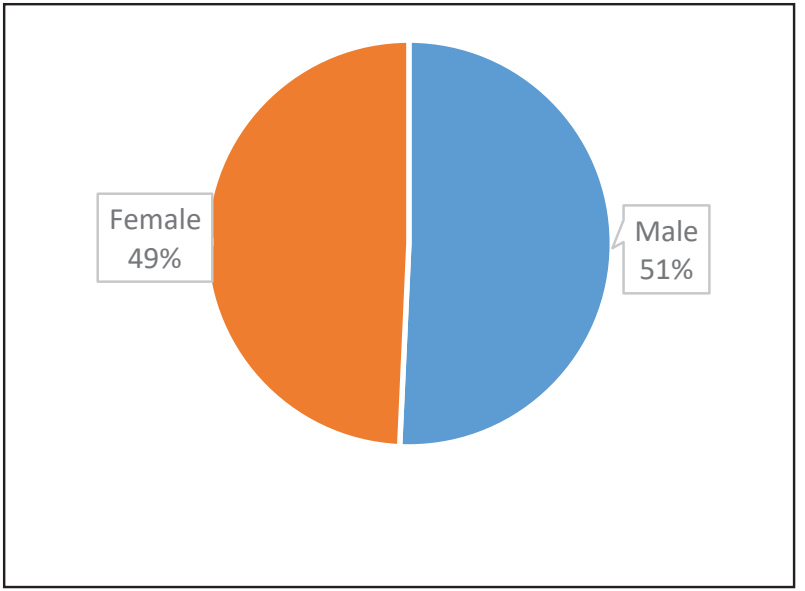

Figure 2: Distribution of participants by Gender.

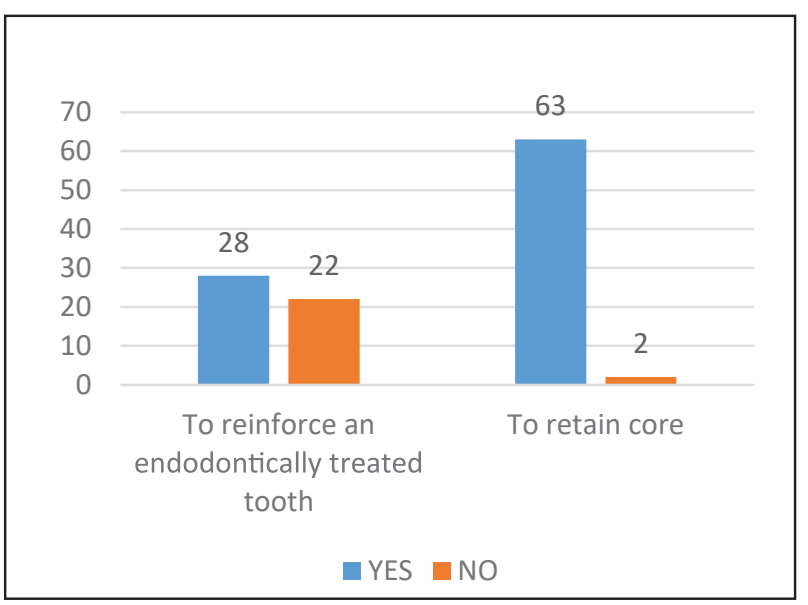

Figure 4. Responses to the question "What do you think is the primary purpose of a post?"

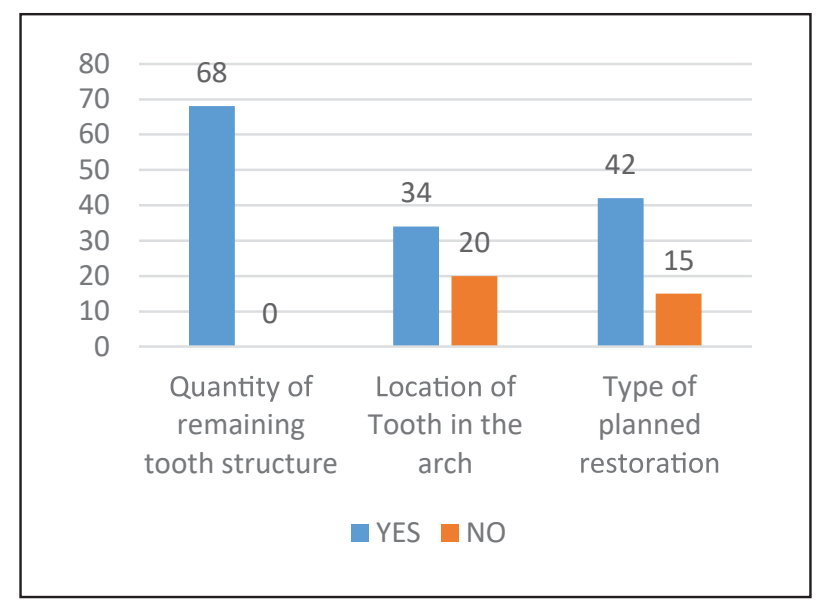

Figure 5. Responses to the question "What decides placement of a post?" 


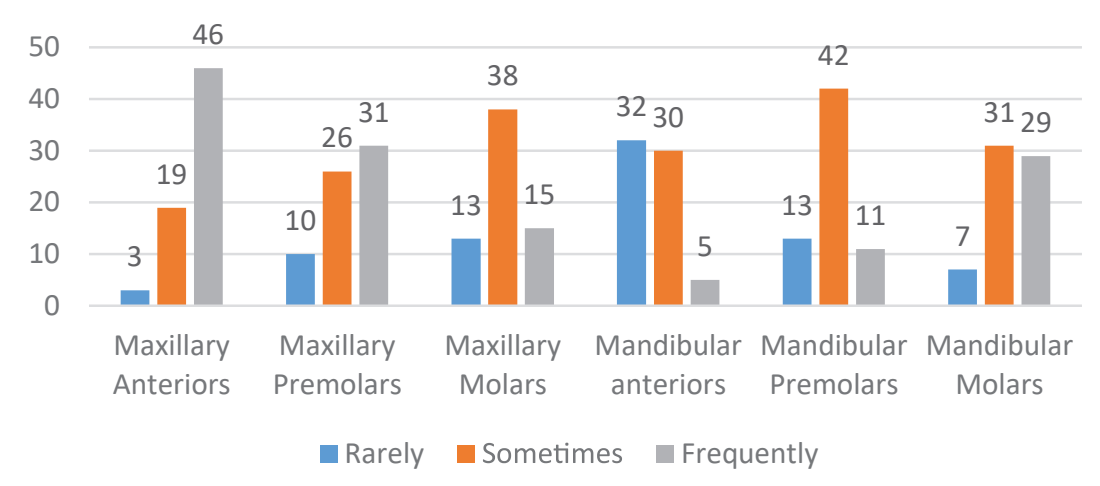

Figure 6: Distribution of frequency of post placement by the participants based on tooth position.

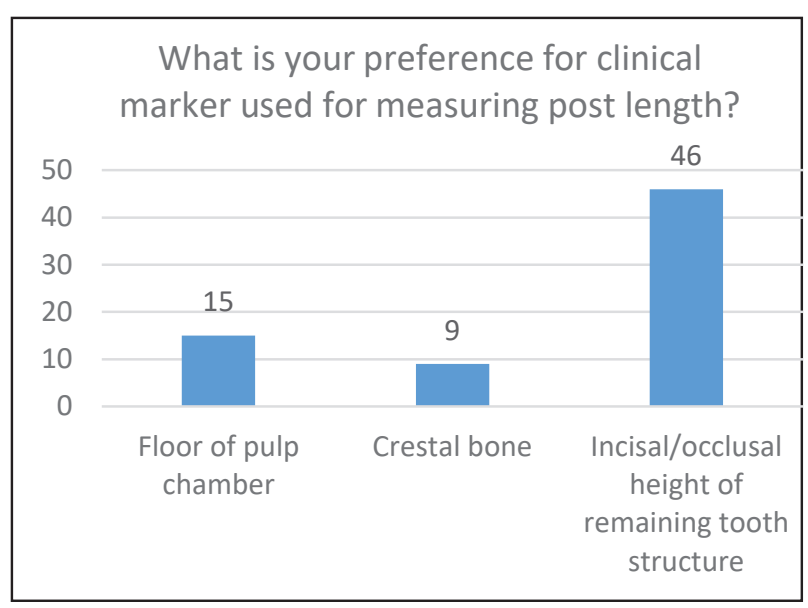

Figure 7: Responses showing preference of clinical marker used for measuring post length.

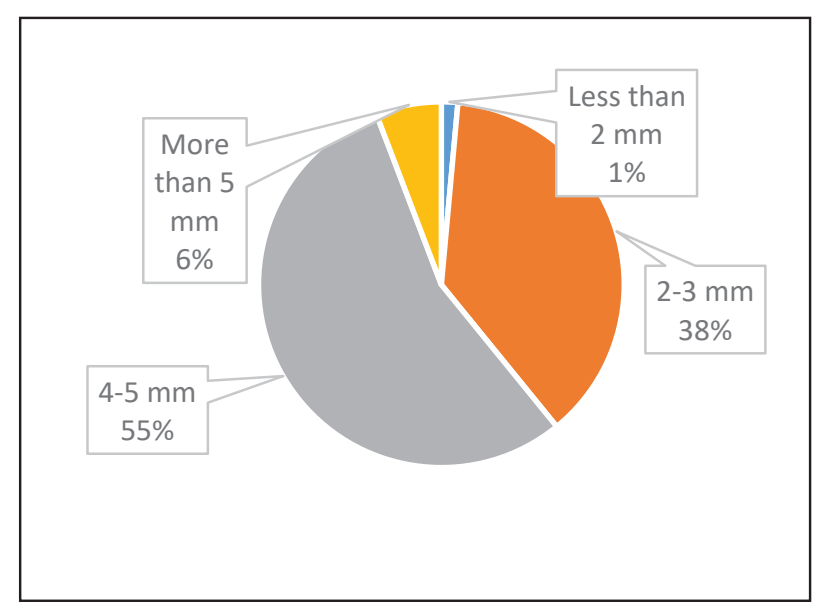

Figure 8. Responses by the participants for amount of apical seal needed (mm of Gutta Percha)

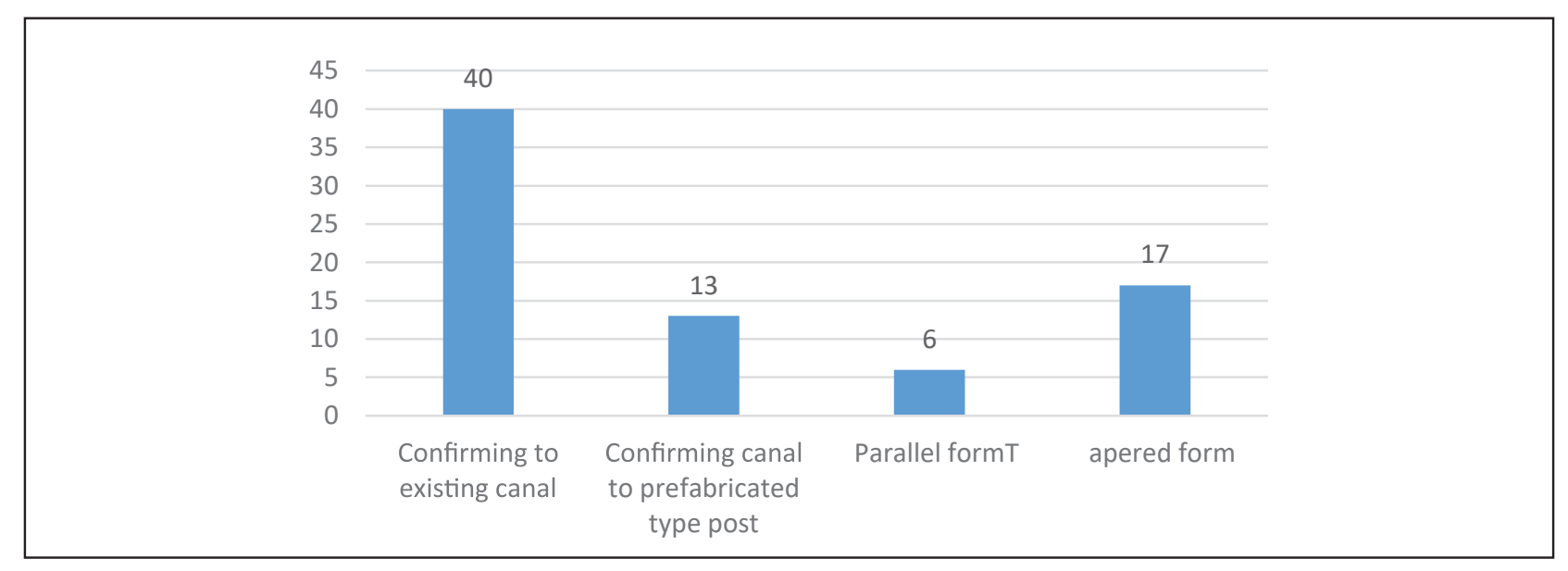

Figure 9. Responses for preference of establishing post geometry 


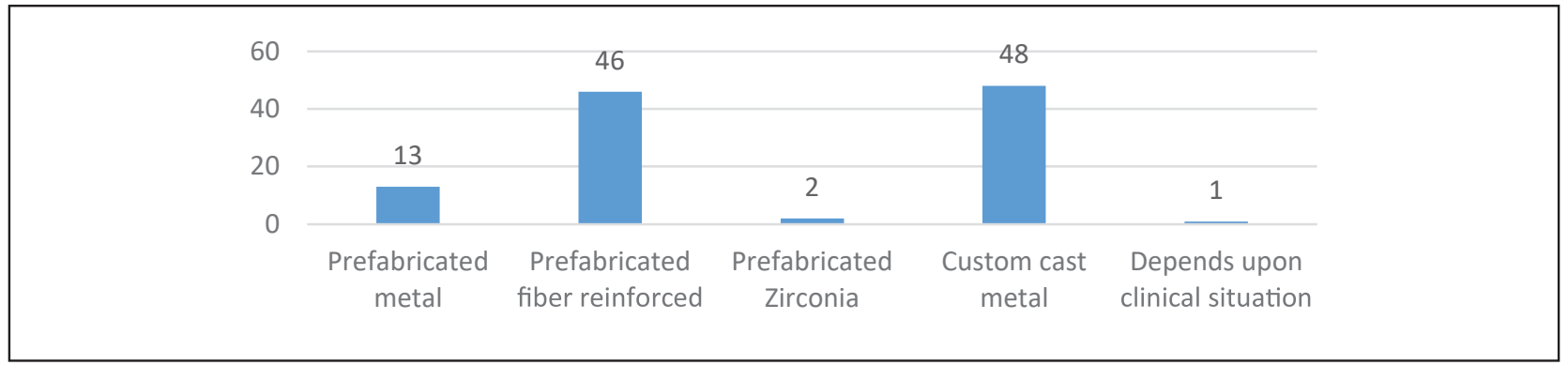

Figure 10. Preference of post type by the participants.

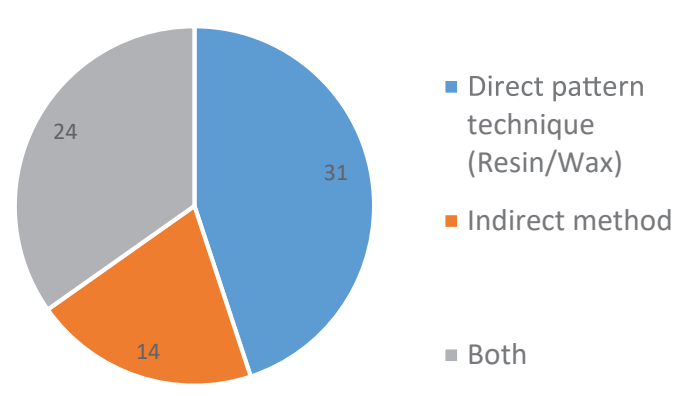

Figure 11. Technique preferred by participants for fabricating custom cast posts

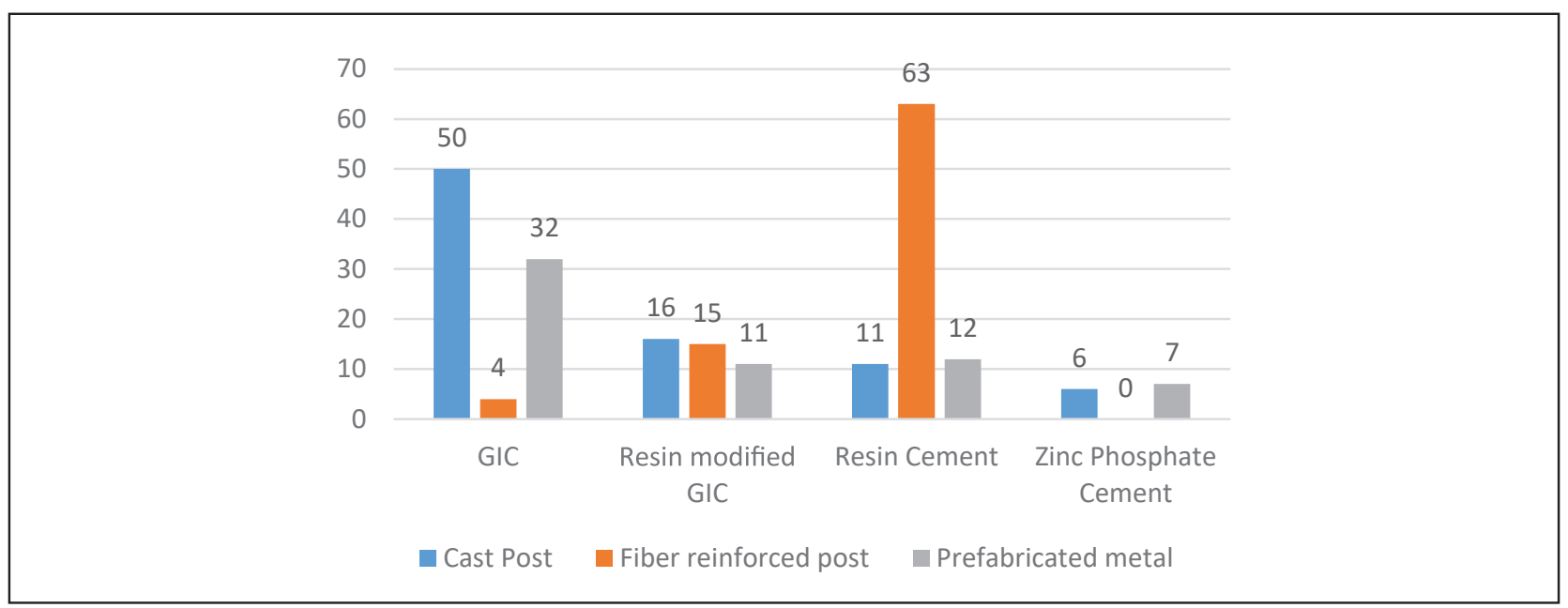

Figure 12. Choice of luting cements by the participants for different types of post

\section{Discussion}

This study was conducted to know the treatment strategies followed and materials preferred for post and core treatment by Nepalese Prosthodontists. The participation rate was $60.52 \%$ out of the 114 -questionnaire sent for the conduction of this study. This response rate is satisfactory and comparable to other similar studies. ${ }^{14-22}$

The majority of Prosthodontists (70.6\%. N=48) in this study were in the age group of $31-40$ years, and their experience was in 1-3 yrs group $(32 \%, \mathrm{~N}=22)$ and $4-6$ yrs group $(33 \%, \mathrm{~N}=23)$ which directs us towards an overview that specialization in Prosthodontics is a developing field in Nepal and almost $2 / 3^{\text {rd }}$ have work experience of less than 6 yrs. This may be due to the start of post graduate program in Prosthodontics in Nepal only after 2010 A.D.

In this study $40 \%$ respondents were involved in teaching institute only, $21 \%$ in both teaching institute and private practice while $16 \%$ were 
involved in government services and 20\% were doing private practice only. This suggests that Prosthodontists in Nepal are practicing in all kind of service centers.

Many past studies and reviews suggest that the primary purpose of a post is to retain a core and seldom to reinforce an endodontically treated tooth. ${ }^{23}$ In the present study almost $91 \%(\mathrm{~N}=63)$ Prosthodontists think that retaining a core is the primary purpose of a post which goes consistent with a study conducted by Ahmed et al where $88 \%$ respondents agreed that primary purpose of a post is to retain a post. ${ }^{20}$

For deciding the clinical situations for placing a post or restoring the tooth without placing it, almost all the Prosthodontists think that the quantity of remaining tooth structure plays an important role. Few of them $(49 \%, \mathrm{~N}=34)$ also think that location of the tooth in the arch and type of planned restoration $(60 \%, \mathrm{~N}=42)$ can also be taken into consideration for deciding to place a post. This finding goes with the published data available which broadly suggests considering the amount of remaining tooth structure to decide whether or not to place a post for an endodontically treated tooth. ${ }^{7,10}$

In the present study there were mixed reactions for the choice of length of post. Most of the respondents think that the post length should be $2 / 3^{\text {rd }}$ the length of root. Similarly, $55 \%$ of the respondents prefer to leave 4-5 $\mathrm{mm}$ Gutta Percha as apical seal. There are various views and recommendations which are published for determining the ideal post length and the amount of remaining Gutta Percha after post space preparation for treating an endodontically treated tooth with a post. ${ }^{6,9,10,15}$ Slutzky-Goldberg I et al suggest that a minimum of $3 \mathrm{~mm}$ of residual gutta percha should be left in the canals after completion of post space preparation. ${ }^{10}$ Similarly Goodacre and Spolnik recommend to retain a minimum of $5 \mathrm{~mm}$ of Gutta Percha apically to maintain a good apical seal. ${ }^{24}$
For determining the post diameter, $56.5 \%$ $(\mathrm{N}=39)$ of the responding Prosthodontists in this study like to confirm it with the existing canal diameter while others had mixed preferences (Table 3). There are various authors who suggest to establish the post diameter without decreasing the periradicular dentine thickness and not compromising the post strength and retention while doing so. ${ }^{24}$ Stern and Hirshfeld suggest the proportionist approach i.e. width shouldn't be greater than one third of the root at its narrowest dimension. Halle EB et al advice to follow the preservationist approach i.e. minimum $1 \mathrm{~mm}$ of dentine should surround the post. Likewise conservationist approach advocated by Pilo and Tamse suggest for minimal canal preparation and maintaining as much residual dentin as possible. ${ }^{25}$

There are various types of post geometry being used while doing post and core treatment. Majority of the respondents $(58 \%, \mathrm{~N}=40)$ in this study preferred to confirm the geometry of the post to existing canal morphology. Literature can be found suggesting various types of post geometry with the most favor given for parallel type of post and least favor for tapered type which is because tapered type of posts are more likely to cause root fracture in comparison to others. $^{26,27}$

Custom cast metal post and prefabricated fiber reinforced post was the most preferred type being used by the respondents of this study. This is similar to other studies conducted in the past. ${ }^{15,20}$ The preference to custom cast metal post may be due to the accuracy of fit of these types of post with the prepared post space while the preference of fiber reinforced type may be because of their similar physical properties with dentine and also the treatment can be finished in the same appointment when post space is prepared.

Various studies in the past have consensus that active type of posts can cause root fracture 
more often than passive type. The preference of the Prosthodontists in this study was more towards serrated/rough (passive) type of post followed by smooth(passive) type while only few preferred to use screw/threaded (active) type of post. Studies show that the frequency of root fracture is less when passive posts are used than using an active one. ${ }^{26,27}$

There is a plethora of luting cement available which is being used for the cementation of post, yet there is no common consensus on which cement is best for which type of post. The respondents in this study have a preference of using GIC for cementing cast posts and prefabricated metal posts while they are using resin cement more often for cementation of fiber reinforced posts. Few respondents also said that they are using Zinc Phosphate cement for cementation of cast posts and prefabricated metal posts. This shows that selection of luting cement may be based on the clinician's perception, preference and experience on how they are practicing placing a post and core. ${ }^{15}$

After cementation of a prefabricated post, there are various materials that can be used to build a core. These materials have their own advantages and disadvantages over one another, which has to be weighed by the practitioner for the specific case scenario. In this present study the participants have more inclination towards using dual cured resin composite material than other materials like light cured composite, amalgam, resin modified GIC and GIC for building core over prefabricated posts. The preference over dual cured resin composite was similar to a study conducted among Australian Prosthodontists by $\mathrm{R}$ Sambrook and M Burrow, ${ }^{15}$ while it was in contrast to a study conducted by Morgano et al in United States where amalgam was more frequently selected. ${ }^{14}$ The respondents of this study not showing interest towards amalgam maybe due to decreased overall use of amalgam owing to the mercury toxicity it possesses.

\section{Conclusion}

Most of the respondents of this study think that the major purpose of a post is to retain a core and not to strengthen an endodontically treated tooth. Similarly majority of them decide to place a post based on the quantity of remaining tooth structure. The most frequent teeth to receive a post are maxillary anteriors and the least frequent teeth are mandibular anteriors. Majority of the Prosthodontists think that the post length should be $2 / 3^{\text {rd }}$ of the root length and they prefer to leave 4-5 $\mathrm{mm}$ of apical GP during post space preparation. The post type of choice is custom cast metal followed by prefabricated fiber reinforced post. The luting cement used more often are resin cement and GIC and for core build-up they use dual cured resin composite more often than other materials.

There were many limitations of this study, one of them is the less number of participants which doesn't give a strong reference to reach a conclusion for deciding which technique or material is better than another. Another limitation is the fact that the information received through questionnaire may not accurately show the actual practice methods used by the respondents in real clinical scenario where a quick decision is needed and the responses given in this study can only be an estimate given by the participants rather than the real clinical figure. Having said that, this study still gives us an overview of how Prosthodontists of Nepal are handling the clinical situations which require a post to be placed in an endodontically treated tooth and this data can be used as a reference for boarder studies among Nepalese Prosthodontists in the future.

\section{References}

1. Cheung W. A review of the management of endodontically treated teeth. Post, core and the final restoration. J Am Dent Assoc. 2005 May;136(5):611-9.

2. Theodosopoulou JN, Chochlidakis KM. A 
systematic review of dowel (post) and core materials and systems. J Prosthodont. 2009 Aug;18(6):464-72.

3. Guzy GE, Nicholls JI. In vitro comparison of intact endodontically treated teeth with and without endo-post reinforcement. J Prosthet Dent. 1979;42(1):39-44.

4. Safavi KE, Dowden WE, Langeland K. Influence of delayed coronal permanent restoration on endodontic prognosis. Endod Dent Traumatol. 1987;3(4):187-91.

5. Alsamadani KH, Abdaziz el-SM, Gad el-S. Influence of different restorative techniques on the strength of endodontically treated weakened roots. Int J Dent. 2012;2012:343712.

6. Mannocci F, Cowie J. Restoration of endodontically treated teeth. Br Dent J. 2014 Mar;216(6):341-6.

7. Morgano SM, Rodrigues AH, Sabrosa CE. Restoration of endodontically treated teeth. Dent Clin North Am. 2004;48(2):vi-416.

8. Goracci C, Ferrari M. Current perspectives on post systems: a literature review. Aust Dent J. 2011 Jun;56 Suppl 1:77-83.

9. Schwartz RS, Robbins JW. Post placement and restoration of endodontically treated teeth: a literature review. J Endod. 2004 May;30(5):289301.

10. Slutzky-Goldberg I, Slutzky H, Gorfil C, Smidt A. Restoration of endodontically treated teeth review and treatment recommendations. Int $\mathrm{J}$ Dent. 2009;2009:150251.

11. Dietschi D, Duc O, Krejci I, Sadan A. Biomechanical considerations for the restoration of endodontically treated teeth: a systematic review of the literature--Part 1. Composition and micro- and macrostructure alterations. Quintessence Int. 2007 Oct;38(9):733-43.

12. Dietschi D, Duc O, Krejci I, Sadan A. Biomechanical considerations for the restoration of endodontically treated teeth: a systematic review of the literature, Part II (Evaluation of fatigue behavior, interfaces, and in vivo studies). Quintessence Int. 2008 Feb;39(2):117-29.

13. Juloski J, Radovic I, Goracci C, Vulicevic ZR, Ferrari M. Ferrule effect: a literature review. J Endod. 2012 Jan;38(1):11-9.
14. Morgano SM, Hashem AF, Fotoohi K, Rose L. A nationwide survey of contemporary philosophies and techniques of restoring endodontically treated teeth. J Prosthet Dent. 1994 Sep;72(3):259-67.

15. Sambrook R, Burrow M. A survey of Australian prosthodontists: the use of posts in endodontically treated teeth. Aust Dent J. 2018 May 9.

16. Hussey DL, Killough SA. A survey of general dental practitioners' approach to the restoration of root-filled teeth. Int Endod J. 1995 Mar;28(2):91-4.

17. Akbar I. Knowledge, attitudes and practice of restoring endodontically treated teeth by dentists in north of saudi arabia. Int J Health Sci (Qassim). 2015 Jan;9(1):41-9.

18. Kon M, Zitzmann NU, Weiger R, Krastl G. Postendodontic restoration: a survey among dentists in Switzerland. Schweiz Monatsschr Zahnmed. 2013;123(12):1076-88.

19. Alenzi A, Samran A, Samran A, Nassani MZ, Naseem M, Khurshid Z, Özcan M. Restoration Strategies of Endodontically Treated Teeth among Dental Practitioners in Saudi Arabia. A Nationwide Pilot Survey. Dent J (Basel). 2018 Sep 3;6(3):44.

20. Ahmed SN, Donovan TE, Ghuman T. Survey of dentists to determine contemporary use of endodontic posts. J Prosthet Dent. 2017 May;117(5):642-645.

21. Naumann M, Kiessling S, Seemann R. Treatment concepts for restoration of endodontically treated teeth: A nationwide survey of dentists in Germany. J Prosthet Dent. 2006 Nov;96(5):3328.

22. Naumann $M$, Neuhaus $K W$, Kölpin $M$, Seemann R. Why, when, and how general practitioners restore endodontically treated teeth: a representative survey in Germany. Clin Oral Investig. 2016 Mar;20(2):253-9.

23. Goodacre CJ, Spolnik KJ. The prosthodontic management of endodontically treated teeth: a literature review. Part I. Success and failure data, treatment concepts. J Prosthodont. 1994 Dec;3(4):243-50.

24. Goodacre CJ, Spolnik KJ. The prosthodontic management of endodontically treated teeth: a 
literature review. Part II. Maintaining the apical seal. J Prosthodont. 1995 Mar;4(1):51-3.

25. Lloyd PM, Palik JF. The philosophies of dowel diameter preparation: a literature review. J Prosthet Dent. 1993 Jan;69(1):32-6.
26. Sorensen JA, Martinoff JT. Clinically significant factors in dowel design. J Prosthet Dent. 1984 Jul;52(1):28-35.

27. Torbjörner A, Karlsson S, Odman PA. Survival rate and failure characteristics for two post designs. J Prosthet Dent. 1995 May;73(5):43944. 